\title{
A Study on Parenting Sense of Competence in Relation to Parenting Counseling
}

\author{
Ie-Soon, Sun1), Soon-Gil, Park2)
}

\begin{abstract}
This study aims to examine differences in parenting sense of competence in relation to parenting counseling. The subjects were 62 mothers of three- to five-year-olds from Jeollanam-do, Korea, and types of children's problematic behaviors were analyzed through a session of 60-minute personal counseling for each person. Before the counseling session began, a questionnaire on parenting sense of competence was distributed and collected to be used in this study. The collected data was processed using descriptive statistics, cross tabulation analysis, T-test and F-test. The research questions of this study are as follows; First, attention deficit and hyperactivity problems were the type of children's problematic behaviors discussed most during counseling. Second, homemakers reported lower parenting sense of competence, parental efficacy and parental anxiety than those of working mothers. Third, mothers of children with sociability and peer relationship problems reported higher parental efficacy and parenting sense of competence, while mothers of children with attention deficit and hyperactivity problems reported higher parental anxiety. These results suggest the need for parent education programs that teach skills to intervene in attention deficit and hyperactivity behaviors for preventing children's problematic behaviors.

Keywords : Parenting Counseling, Types of Children's Problematic Behaviors Discussed during Counseling, Parenting Sense of Competence, Parental Anxiety, Parental Efficacy
\end{abstract}

\section{Introduction}

Humans are cared for and educated on basic things necessary to live in the environments they first experience upon birth. A model for the children, the mother serves as a caregiver, a moral trainer, a facilitator of self-concept development, an autonomy development helper and a learning experience provider[1]. Mothers are now actively taking part in the society and the

Received(April 22, 2019), Review Result(1st: May 14, 2019, 2nd: July 6, 2019), Accepted(September 10, 2019)

1) (Student) 62271 Doctor's Course, Nambu Univ., 23 Chumdan Jungang-ro, Gwangsan-gu, Gwangju, South Korea

email: ksis1207@hanmail.net

2) (Professor, Corresponding Author) 62271 Dept. of Elementary Special Education, Nambu Univ., 23 Chumdan Jungang-ro, Gwangsan-gu, Gwangju, South Korea

email: psoongil@nambu.ac.kr 
role of mothers in families are being transferred to educational institutes for young children, and thus, the scope of interaction and contact with peers are becoming wider. As young children spend more time in institutions aside from their home during their developmental stage, various problematic behaviors such as conflicts and anxiety are appearing, and mothers are experiencing more parentingissues by children accordingly[2].

Problematic behaviors often exhibited by children vary in degree and kind. Children with problematic behaviors suffer adaptive problems in terms of personal, social and physical aspects and may build barriers between themselves and the external world in peer environments or learning environments through inappropriate, aggressive or withdrawn actions[3].

During early development, the mother's overly high expectations of the child and excessive parenting methods affect the child's peer relationships and sociability[4][5]. The study by [6] found that the mother's expectations of the child are related to daily life rules and problematic behaviors of infants and children. Children learn about appropriate and inappropriate behavior through parents' parenting behavior. And they develop their personalities while obtaining knowledge from their mothers, that is, the primary caregiver, and preparing the foundation of socialization at home[7]. Therefore, children's frustration caused by parents' wrong parenting behaviors or overly high expectations is the cause of their problematic behaviors.

When a child's language or behavior deviates from social expectations or norms and such problem is not solved appropriately, the child may experience various increasing maladjustment problems in terms of physical, sociability, emotional and cognitive aspects. There are a number of causes of problematic behaviors, and one of them is the mother's parenting methods. When the mother does not use proper parenting methods, the child can develop hyperactivity and impulsiveness, which increase negative and aggressive interactions. As a result, the child is likely to be ostracized by not only his or her siblings but also peers[8].

The more positive a child's peer relationship, the less the child's problematic behaviors are likely to occur. The more negative a child's peer relationship, the more the child's problematic behaviors are likely to occur. And the mother's rejective and controlling parenting methods were found to affect the child's anxiety, hostility and defiant behavior. On the other hand, the mother's receptive and autonomous parenting methods were found to be highly correlated with a decrease in aggressiveness, anxiety and frustration[9].

The mother's parenting sense of competence affects and is affected by various variables, such as the mother's age, highest level of education, employment status and the child's age and gender[10].

When all these are considered, the major factor affecting a child's problematic behavior is 
parenting methods of the mother as the primary caregiver. When the mother's parenting methods are improved, the child's problematic behaviors change rapidly[11]. In particular, the mother needs to supplement her insufficient parenting knowledge or skills through parenting counseling and get help if they have wrong values or parenting behaviors and methods.

Through parenting counselling, it is possible to reduce the risks of problematic behaviors of young children and improve the possibility for positive changes with an efficient coping strategy of mothers. Therefore, this study is meaningful in that it identifies the problematic behavior types of young children from the parenting counselling of mothers, develops education for early childhood parents and various programs while maintaining positive relationships on parenting.

The research questions of this study are as follows.

The first question is "What types of children's problematic behavior were found in parenting counseling with mothers?"

The second question is "How was the parenting sense of competence of the parents who participated in the parenting counseling?"

\section{Research Methods}

\subsection{Research Subjects}

The research subjects were 62 mothers of three- to five-year-olds who were enrolled in five nursery schools located in $\mathrm{M}$ city, J province. The characteristics of research subjects are shown in [Table 1].

[Table 1] Characteristics of Research Subjects

\begin{tabular}{|c|c|c|c|}
\hline \multicolumn{2}{|c|}{ Variable } & $\begin{array}{c}\text { Frequency } \\
\text { (number of persons) }\end{array}$ & Ratio (\%) \\
\hline \multirow{4}{*}{ Age } & Younger than 30 years old & 5 & 8.1 \\
\cline { 2 - 4 } & $\begin{array}{c}\text { Older than 30 years old and } \\
\text { younger than 40 years old }\end{array}$ & 48 & 77.4 \\
\cline { 2 - 4 } & 40 years or older & 9 & 14.5 \\
\hline \multirow{2}{*}{$\begin{array}{c}\text { Highest level of } \\
\text { education }\end{array}$} & High school graduates or less & 17 & 27.4 \\
\cline { 2 - 4 } & Vocational college graduates & 19 & 30.6 \\
\hline \multirow{2}{*}{$\begin{array}{c}\text { Employment } \\
\text { status }\end{array}$} & College graduates or higher & 26 & 41.9 \\
\cline { 2 - 4 } & Homemaker & 55 & 11.3 \\
\hline $\begin{array}{c}\text { Parenting } \\
\text { counseling }\end{array}$ & Working mother & 7 & 38.7 \\
\hline
\end{tabular}




\begin{tabular}{|c|c|c|c|}
\hline experience & No & 38 & 61.3 \\
\hline \multirow{3}{*}{ Child's age } & 3 years old & 25 & 40.4 \\
\hline & 4 years old & 18 & 29.0 \\
\hline & 5 years old & 19 & 30.6 \\
\hline \multirow{4}{*}{$\begin{array}{c}\text { Major types of } \\
\text { children's } \\
\text { problematic } \\
\text { behavior }\end{array}$} & Sociability and peer problems & 5 & 8.1 \\
\hline & $\begin{array}{l}\text { Language and communication } \\
\text { problems }\end{array}$ & 9 & 14.5 \\
\hline & $\begin{array}{c}\text { Attention deficit and hyperactivity } \\
\text { problems }\end{array}$ & 34 & 54.8 \\
\hline & $\begin{array}{l}\text { Parent-child and sibling relationship } \\
\text { problems }\end{array}$ & 14 & 22.6 \\
\hline \multicolumn{2}{|r|}{ Total } & 62 & 100 \\
\hline
\end{tabular}

\subsection{Research Instrument}

This study used a scale by [12] who adapted and revised the Parenting Sense of Competence (PSOC) scale. The questionnaire used in this study consists of items intended to measure Parenting Sense of Competence-Efficacy (PSOC-E) on an emotional level, and is a self-report questionnaire. Examples of the questionnaire items include: "I think I am competent in taking care of children," "I know well about what I have to do as a parent," and "I am worried that I would not be a good parent." The 14-item questionnaire measures responses on a 5-point Likert scale ranging from strongly disagree (1) to strongly agree (5). When computing the total score, items measuring parents' anxiety were reversely scored. A higher total score was interpreted as showing higher parenting sense of competence. The reliability of the research instrument measuring parenting sense of competence was tested using Cronbach's alpha coefficient. The Cronbach's alpha for the total score of parenting sense of competence was 0.76; and the Cronbach's alpha coefficients for the two sub-categories of parental efficacy and parental anxiety were 0.78 and 0.67 , respectively.

[Table 2] Items to Measure Parenting Sense of Competence and Their Reliability

\begin{tabular}{|c|c|c|c|}
\hline Variable & Item & Number of items & Cronbach's a \\
\hline Parental efficacy & $1,2,3,4,5,6,7^{*}, 8^{*}, 9,14$ & 10 & .78 \\
\hline Parental anxiety & $10^{*}, 11^{*}, 12^{*}, 13^{*}$ & 4 & .67 \\
\hline \multicolumn{2}{|c|}{ Total } & 14 & .76 \\
\hline
\end{tabular}

*Items scored reversely 


\subsection{Research Procedure and Data Processing}

This study was conducted for three months from Sep. 5 to Nov. 30, 2016, and the researchers visited five private nursery schools located in $\mathrm{M}$ city, $\mathrm{J}$ province, to obtain consent from the nursery schools and the mothers. A session of parenting counseling was provided for a total of 62 participants. The collected data was statistically processed using the SPSS WIN 18.0 program, descriptive statistics, cross analysis, T-test, ANOVA, and Scheffe's post-validation.

\section{Research Results}

\subsection{Types of Children's problematic behaviors Discussed during Counseling in relation to Their Background Variables}

[Table 3] shows the results of the analysis of children's problematic behaviors discussed during counseling in relation to their background variables.

[Table 3] Types of Children's problematic behaviors Discussed during counseling in relation to Their Background Variables

\begin{tabular}{|c|c|c|c|c|c|c|c|c|}
\hline \multicolumn{2}{|c|}{ Classification } & $\begin{array}{l}\text { Sociability and } \\
\text { peer problems }\end{array}$ & $\begin{array}{c}\text { Language and } \\
\text { communicatio } \\
\mathrm{n} \text { problems }\end{array}$ & $\begin{array}{c}\text { Attention } \\
\text { deficit and } \\
\text { hyperactivity } \\
\text { problems }\end{array}$ & $\begin{array}{l}\text { Parent-child } \\
\text { and sibling } \\
\text { relationship } \\
\text { problems }\end{array}$ & Total & $x^{2}$ & $p$ \\
\hline \multirow{3}{*}{ Age } & 3 & $1(1.6)$ & $1(1.6)$ & $18(29.0)$ & $5(8.1)$ & $25(40.3)$ & \multirow{3}{*}{7.21} & \multirow{3}{*}{.301} \\
\hline & 4 & $2(3.2)$ & $3(4.8)$ & $8(12.9)$ & $5(8.1)$ & $18(29.0)$ & & \\
\hline & 5 & $2(3.2)$ & $5(8.1)$ & $8(12.9)$ & $5(8.1)$ & $19(30.6)$ & & \\
\hline \multirow{2}{*}{ Gender } & Male & $2(3.2)$ & $7(11.3)$ & 19(30.6) & $9(14.5)$ & $37(59.7)$ & \multirow{2}{*}{2.35} & \multirow{2}{*}{.502} \\
\hline & Female & $3(4.8)$ & $2(3.2)$ & $15(24.2)$ & $5(8.1)$ & $25(40.3)$ & & \\
\hline \multirow{2}{*}{$\begin{array}{l}\text { Birth } \\
\text { order }\end{array}$} & First-born & $4(6.5)$ & $6(9.7)$ & $23(37.1)$ & $6(9.7)$ & $39(62.9)$ & \multirow[b]{2}{*}{3.42} & \multirow[b]{2}{*}{.331} \\
\hline & $\begin{array}{c}\text { Second-b } \\
\text { orn }\end{array}$ & $1(1.6)$ & $3(4.8)$ & $11(17.7)$ & $8(12.9)$ & $23(37.1)$ & & \\
\hline \multicolumn{2}{|c|}{ Total } & $5(8.1)$ & $9(14.5)$ & $34(54.8)$ & $14(22.6)$ & $62(100.0)$ & & \\
\hline
\end{tabular}

[Table 3] shows the results of the analysis of the types of children's problematic behaviors in relation to their background variables. Age had a high correlation with attention deficit and hyperactivity problems. Eighteen three-year-olds (29.0\%), eight four-year-olds (12.9 \%), and eight five-year-olds $(12.9 \%)$ were reported to have attention deficit and hyperactivity problems. Gender also had a high correlation with attention deficit and hyperactivity problems. Nineteen males $(30.6 \%)$ and 15 females $(24.2 \%)$ were reported to have attention deficit and 
hyperactivity problems. Birth order also had a high correlation with these two types of problems. There were 23 first-born children (37.1\%) and 11 second-born children (17.7\%) who were reported to have attention deficit and hyperactivity problems. From this, it can be seen that attention deficit and hyperactivity problems were discussed most in parenting counseling.

\subsection{Comparison of the Parenting Sense of Competence between the Parents who Participated in Parenting Counseling}

This study analyzed the parenting sense of competence of the parents who participated in parenting counseling in relation to their employment status and types of children's problematic behaviors discussed during counseling. The results are shown in Tables 4 and 5 .

[Table 4] Difference in Parenting Sense of Competence between Homemakers and Working Mothers

\begin{tabular}{|c|c|c|c|c|c|}
\hline Variable & Employment status & $\mathrm{M}$ & SD & $t$ & $\mathrm{p}$ \\
\hline \multirow{2}{*}{ Parental Efficacy } & Homemaker & 3.91 & .37 & \multirow{2}{*}{$-4.60^{* * *}$} & \multirow{2}{*}{.000} \\
\hline & Working mother & 4.61 & .37 & & \\
\hline \multirow{2}{*}{ Parental Anxiety } & Homemaker & 4.33 & .46 & \multirow{2}{*}{$-2.12^{*}$} & \multirow{2}{*}{.038} \\
\hline & Working mother & 4.71 & .17 & & \\
\hline \multirow{2}{*}{$\begin{array}{l}\text { Parenting sense of } \\
\text { competence }\end{array}$} & Homemaker & 4.12 & .29 & \multirow{2}{*}{$-4.66^{* * *}$} & \multirow{2}{*}{.000} \\
\hline & Working mother & 4.66 & .24 & & \\
\hline
\end{tabular}

${ }^{*} \mathrm{p}<.05 \quad * * * \mathrm{p}<.001$

[Table 4] shows differences in mothers' parenting sense of competence in relation to their employment status. First, there was a statistically significant difference in parental efficacy between the two groups-homemakers and working mothers $(t=-4.60, p<.001)$. Homemakers $(\mathrm{M}=3.91)$ reported lower parental efficacy than that of working mothers $(M=4.61)$. A statistically significant difference was also found between the two groups in terms of parental anxiety $(\mathrm{t}=-2.12, \mathrm{p}<.05)$. Homemakers $(\mathrm{M}=4.33)$ reported lower parental anxiety than that of working mothers $(M=4.71)$. And a statistically significant difference was found between the two groups in terms of parenting sense of competence $(\mathrm{t}=-4.66, \mathrm{p}<.001)$. Homemakers $(\mathrm{M}=4.12)$ were found to have lower parenting sense of competence than that of working mothers $(M=4.66)$.

Therefore, it can be said that homemakers have lower parenting sense of competence, parental efficacy and parental anxiety than those of working mothers. 
[Table 5] Difference in the Parenting Sense of Competence between the Parents in Relation to Major Types of Children's Problematic Behaviors Discussed during Counseling

\begin{tabular}{|c|c|c|c|c|c|c|}
\hline Variable & Types of children's problematic behaviors & $\mathrm{M}$ & SD & $\mathrm{F}$ & $\mathrm{p}$ & Scheffe \\
\hline \multirow{5}{*}{$\begin{array}{l}\text { Parental } \\
\text { efficacy }\end{array}$} & Sociability and peer problems (a) & 4.50 & .43 & \multirow{5}{*}{$4.01^{*}$} & \multirow{5}{*}{. 012} & \multirow{5}{*}{$\begin{array}{l}a>c \\
a>d\end{array}$} \\
\hline & Language and communication problems (b) & 4.18 & .51 & & & \\
\hline & Attention deficit and hyperactivity problems (c) & 3.91 & .40 & & & \\
\hline & Parent-child and sibling relationship problems (d) & 3.88 & .32 & & & \\
\hline & Total & 3.99 & .43 & & & \\
\hline \multirow{5}{*}{$\begin{array}{c}\text { Parental } \\
\text { anxiety }\end{array}$} & Sociability and peer problems (a) & 4.60 & .22 & \multirow{5}{*}{$4.24^{* *}$} & \multirow{5}{*}{.009 } & \multirow{5}{*}{$b<c$} \\
\hline & Language and communication problems (b) & 3.91 & 1.01 & & & \\
\hline & Attention deficit and hyperactivity problems (c) & 4.44 & .22 & & & \\
\hline & Parent-child and sibling relationship problems (d) & 4.42 & .20 & & & \\
\hline & Total & 4.37 & .42 & & & \\
\hline \multirow{5}{*}{$\begin{array}{l}\text { Parenting } \\
\text { sense of } \\
\text { competen }\end{array}$} & Sociability and peer problems (a) & 4.55 & .29 & \multirow{5}{*}{$2.91^{*}$} & \multirow{5}{*}{.050} & \multirow{5}{*}{$a>b$} \\
\hline & Language and communication problems (b) & 4.05 & .53 & & & \\
\hline & attention deficit and hyperactivity problems (c) & 4.17 & .28 & & & \\
\hline & Parent-child and sibling relationship problems (d) & 4.15 & .22 & & & \\
\hline & Total & 4.18 & .33 & & & \\
\hline
\end{tabular}

[Table 5] shows differences in mothers' parenting sense of competence in relation to types of children's problematic behaviors discussed during counseling. There was a statistically significant difference in parental efficacy between the four groups $(\mathrm{F}=4.01, \mathrm{p}<.05)$. Mothers of children with sociability and peer problems $(M=4.50)$ reported higher parenting sense of competence than those of mothers of children with attention deficit and hyperactivity problems $(\mathrm{M}=3.91)$ and with parent-child and sibling relationship problems $(\mathrm{M}=3.88)$. There was a statistically significant difference in parental anxiety between the groups $(\mathrm{F}=4.24, \mathrm{p}<.01)$. Mothers of children with attention deficit and hyperactivity problems $(M=4.44)$ had higher parental anxiety than that of mothers of children with language and communication problems $(\mathrm{M}=3.91)$. A statistically significant difference was found between the groups in terms of parenting sense of competence $(\mathrm{F}=2.91, \mathrm{p}<.05)$. Mothers of children with sociability and peer relationship problems $(\mathrm{M}=4.55)$ reported higher parenting sense of competence than that of mothers of children with language and communication problems ( $M=4.05)$.

Therefore, it can be said that mothers of children with sociability and peer problems have high parental efficacy and parenting sense of competence, while those of children with attention deficit and hyperactivity problems have high parental anxiety.

\section{Conclusion}

First, age, gender and birth order had the highest correlation with attention deficit and hyperactivity problems among children's problematic behaviors discussed during counseling. 
First born male children who were aged three were discussed most during counseling. From this, it can be inferred that mothers tend to control and refuse their male children's active and aggressive behaviors, while mothers' parenting pattern for their female children tend to be receptive[8].

For first borns, the parents may have insufficient knowledge about parenting methods and have great expectations of their children in hopes of raising them well[4][5]. Such attention to children may lead to autonomy or neglect for behaviors and cause attention deficit and hyperactivity problems as they interact with peers at nursery schools. This accords with studies on causes of children's problematic behaviors that show that change in family forms, pressure due to the mother's high expectations[4][6], and inappropriate discipline methods can increase the child's anxiety, hostility and defiant behavior[9]. Therefore, the mother's proper disciplines can help form a positive mother-child relationship.

Second, it was found that working mothers had more positive parenting sense of competence than that of homemakers. Working mothers reported that they know well about their children, identify well what difficulties their children have, and have the necessary knowledge to be a good parent. In contrast, working mothers felt they did not achieve anything as parents, felt nervous and anxious as parents and felt frustrated when their children were not following their rules or instructions.

Third, there were differences in parenting sense of competence in relation to types of children's problematic behaviors. The higher the score of sociability and peer problems, the higher parental efficacy; the higher the score of attention deficit and hyperactivity problems, the higher parental anxiety.

It was found through parenting counseling that mothers' parenting methods affect children and more parenting counseling should be provided. It was also found that mothers with less or younger children are more concerned with children's problematic behaviors. This seems to accord with a study that found that when in term of mothers' parenting, an appropriate stimulus is provided to children, it helps to reduce children's problematic behaviors and improve their adaptability[5] and a study that found mothers' parenting attitude affects children's problematic behaviors and prosocial behaviors[11]. In conclusion, this study has identified the importance of providing knowledge on children's development, interaction skills and methods to solve children's problematic behaviors through parenting counseling, thus suggesting the need for more active support of parent education programs and the provision of methods to solve children's problematic behaviors.

The following suggestions can be made based on the results of this study. First, care needs 
to be taken when applying the results of this study to all three- to five-year-olds because the analysis is limited to problematic behaviors of children, who were enrolled in nursery schools located in a specific area, discussed in personal parenting counseling. Second, it has been generalized that children spend long hours at child care institutions. This requires methods for teachers to early intervene in children's problematic behaviors because such problematic behaviors may develop into misbehavior or delinquency unless children are disciplined early about their problematic behaviors.

\section{Reference}

[1] Do-hui Oh, A Study on the Relationships between Rearing Attitude of Mother, Self-Regulating and Ability to Solve Interpersonal Problem, Major in Early Childhood Education Graduate School of Education, Chungnam National University, Master's thesis, (2012)

[2] Oh Yeon taek, Yeon Gyu Seung, An Analysis of the Relationships among Parenting Stress of mothers, Self-Esteem of children, Externalizing problem behavior and Intellectual capacity of children, Journal of Parent Education, (2018), Vol.10, No.1, pp.31-50.

[3] Kim Yeon, A study on the relationships of the child's temperament, psychological family environment variables and behavior problems, Kyonggi University, Ph.D Thesis, (2008)

[4] Myoung Jin Lee, Comparison of mother's expectation, parenting-attitudes and children behavior problems on the mother characteristics, Chung-Ang University, Master's thesis, (2014)

[5] Ju Yeon Jung, Jung Min Kim, Chae Young Hong, The Effect of Preschoolers' Temperament and Parental Intelligence on Their Behavior Problems: Mediating Effect of Preschoolers' Resilience, Journal of Emotional \& Behavioral Disorders, (2017), Vol.33, No.1, pp.217-239, DOI: 10.33770/JEBD.33.1.12

[6] Sung-Sook Pu, Eun-jung Yoon, The impact of mothers' expectation on their everyday rules and children's behavior problems, Korean Journal of Early Childhood Education, (2018), Vol.38, No.1, pp.115-137, DOI: 10.18023/kjece.2018.38.1.005

[7] J. F. Mattanah, Parental Psychological Autonomy and Children's Academic Competence and Behavioral Adjustment in Late Childhood: More Than Just Limit-Setting and Warmth, Merrill-palmer Quarterly, (2001), Vol.47, No.3, pp.355-376.

[8] Sujin Kwon, Se ni Oh, Sanghee Lee, A Study on Related Variables to Young Children's Behaviors Problems: Children's, Mothers', and Peer Relationships' Variables, Journal of Future Early Childhood Education, (2016), Vol.23, No.4, pp.385-406, DOI: 10.22155/JFECE.23.4.385.406

[9] Sook Gyeong Yoo, Seung Hee Lee, Relationships between Child's Emotional/Behavioral Problems and Mother's Parenting Style Based on K-CBCL 1.5-5 and Gottman's Types of Parenting Styles, Journal of Emotional \& Behavioral Disorders, (2012), Vol.28, No.2, pp.1-22, UCI: G704-000501.2012.28.2.011

[10] Hye-Young Lee, Effects of Parenting Support Program in Day-care Center on the Parents' Parenting 
Efficacy and Their Young Children's Peer Competency, Education Graduate School, Dongguk University, Master's thesis, (2019)

[11] Sung Sook Gong, Ji Young Lim, The effect of preschooler's temperament and maternal parenting attitude on preschooler's problem and prosocial behaviors -Focusing on the mediating effect of cool executive function-, Korean Journal of Early Childhood Education, (2012), Vol.32, No.2, pp.351-375, DOI: 10.18023/kjece.2012.32.2.016

[12] Suk Jae Shin, Moon Ja Chung, Effects of Stress, Social Support and Efficacy on Mothers' Parenting Behaviors, Korean Journal of Child Studies, (1998), Vol.19, No.1, pp.27-42. 